\title{
Reactive Case Detection of Asymptomatic Malaria in Households and Neighbors of Laboratory Confirmed Cases in Raya Kobo District, Northeast Ethiopia
}

\author{
Yimer Melese \\ Dessie Health Science College \\ megbaru alemu abate ( $\nabla$ mgbeyney@gmail.com ) \\ Bahir Dar University https://orcid.org/0000-0002-4851-1366 \\ Mulat Yimer \\ Bahir Dar University \\ Banchamlak Tegegne \\ Amhara Public Health Institute
}

Research article

Keywords: Asymptomatic malaria, Reactive case detection, Index case, Raya Kobo

Posted Date: December 30th, 2019

DOl: https://doi.org/10.21203/rs.2.19723/v1

License: (c) (i) This work is licensed under a Creative Commons Attribution 4.0 International License.

Read Full License 


\section{Abstract}

Background Malaria is the leading vector borne parasitic disease causing enormously high morbidity and mortality worldwide. There have been huge efforts so far to control and eliminate malaria in the world. However, high prevalence of asymptomatic carriage poses a threat on malaria control and elimination programs. Since asymptomatic infections present no overt sign and symptoms, they do not get clinical attention. Moreover, asymptomatic cases are a potential source of infection in high and low transmission settings. Despite the presence of some pocket data, the prevalence of asymptomatic carriage has not yet been known nationally and the current study area as well. Therefore, we aimed to assess the prevalence of asymptomatic malaria cases and associated factors in households and neighbors of laboratory confirmed cases in Raya Kobo district, Northeast Ethiopia.

Methods: A community based cross-sectional study was conducted from February to April, 2019 among 270 study participants selected by convenient sampling technique at the community where laboratory confirmed cases were found. A structured questionnaire was used to collect data on socio-demographic characteristics, individual and household level factors. The data were entered in Epi Data 3.1 version and analyzed by using SPSS version 20 . Variables with $P<0.25$ in the bivariable analysis were taken to the multivariable analysis to control potential confounders, and $p<0.05$ was considered statistically significant.

Results: The overall prevalence of asymptomatic malaria was $7.0 \%$, with $3.0 \%, 5.2 \%$ and $12.0 \%$, respectively by Rapid diagnostic tests (RDT), Microscopy and Polymerase chain reaction (PCR). Majority of the infections (73.7\%) were identified from index households. PCR detected asymptomatic infections about 2.7 and 2.3 folds higher than RDT and microscope, respectively. Previous malaria history (AOR: 4.030, 95\% Cl: 1.021-15.903), living with index cases (AOR: $3.880,95 \% \mathrm{Cl}: 1.275-11.806$ ) and family size > 6 members (AOR: 4.820, 95\% Cl: 1.260-18.437) were significant predictors of Plasmodium spp infection.

Conclusion: Reactive case detection had identified considerably higher asymptomatic malaria cases at the community. Therefore, active case investigation should be established in the community by tracking the symptomatic cases at the health facilities. Diagnostic tests involving the PCR should be implemented in the surveillance of asymptomatic malaria. Active malaria cases should also be treated.

\section{Background}

Malaria is a life-threatening vector borne disease caused by protozoan parasite of the genus Plasmodium through the bite of female Anopheles mosquitoes. Malaria is a serious public health problem in many parts of the world, exacting an unacceptable toll on the health and economic welfare of the world's poorest communities. Based on the WHO report, there were an estimated 216 million episodes of malaria in 2016, of which approximately $90 \%$, or 194 million cases were in the African Region. There were an estimated 445000 malaria deaths in 2016, of which 91\% were in Africa. Approximately $90 \%$ of malaria deaths globally were of children under 5 years of age and pregnant women (1). In Ethiopia, nearly $75 \%$ of 
the country's land mass where $68 \%$ of the population lives is potentially malarious. Overall, malaria accounts for approximately $5 \%$ of outpatient consultations, $2.4 \%$ of admissions and $2.5 \%$ of inpatient deaths in the country. Plasmodium falciparum and Plasmodium vivax are the two predominant Plasmodium species distributed all over the country, accounting for $60 \%$ and $40 \%$ of malaria cases, respectively. The main malaria control strategies in Ethiopia includes but not limited to early diagnosis and prompt treatment, vector control, epidemic management and personal protection through the use of insecticide treated nets (2).

Scale up of malaria laboratory diagnostic approaches has given better opportunities to improve early detection of the parasite and treatment, which is the pillar of malaria elimination. Malaria microscopy and Rapid diagnostic tests (RDTs) are the most widely used diagnostic methods for clinical malaria and routine surveillance (3). However, low density infections have a tendency to be missed by these methods. On the other hand, the increased use of nucleic acid amplification based and loop-mediated isothermal amplification methods reveal tremendous improvements in the investigation of asymptomatic malaria cases $(4,5)$.

Malaria control activities have brought substantial reduction of malaria incidence for the last decade through different strategic intervention including environmental management, indoor residual spraying, long lasting insecticide treated nets and early diagnosis and prompt treatment (6). Ethiopia has achieved a $50 \%$ reduction of malaria cases and deaths with scale-up of malaria interventions (7). As malaria transmission declines, the distribution increasingly turned out to be focal to certain geographical areas and demographic groups $(8,9)$.

The presence of high prevalence asymptomatic carriage poses a threat on malaria elimination and control program (10). Since asymptomatic infection present no overt sign and symptoms, they do not get clinical attention. Moreover, asymptomatic cases are a potential source of infection in high and low transmission setting (11).

The longtime asymptomatic carriage potentially bridges during lengthy dry season until the next transmission time, where Anopheles mosquitoes increase in number by harboring the gametocytes stage to continue the cycle (12). Although the scale up of malaria interventions resulted subsequent reduction of malaria cases, the program demands the adoption of new strategies and introduction of new activities for the transition of malaria control to elimination phase (13). To interrupt the ongoing malaria transmission in moderate and low endemic setting, malaria elimination program need to target the detection of asymptomatic infection in the general population through active rather than passive case detection (14).

Despite the presence of some pocket data, the prevalence of asymptomatic carriage has not been yet known nationwide and at the study area in particular. Conventionally, Ethiopia has used passive case detection and only catches up symptomatic cases who seek diagnosis and treatment after visiting the health facility (2). Therefore, the aim of this study was to assess asymptomatic malaria in households 
and neighbors of laboratory confirmed cases in catchment kebeles of two selected health centers in Raya Kobo district.

\section{Materials And Methods}

\section{Study design, period and area}

This cross-sectional study was conducted in the catchment kebeles of two The altitude of the area ranges from 1100 to 3000 meters above sea level. The mean monthly temperature of the study area ranges between $19.5^{\circ} \mathrm{C}$ in December to $26.21^{\circ} \mathrm{C}$ in June. The annual rainfall ranges from $411.51 \mathrm{~mm}$ to $1651.02 \mathrm{~mm}$, and the average annual rainfall is $907.12 \mathrm{~mm}$. Likewise, the major transmission season of malaria in Raya Kobo district occurs from September to December after major rainfalls (June to September) followed by April to May with minor transmission (15). According to the 2007 census conducted by the Central Statistical Agency of Ethiopia (CSA), the district had a total of 221,958 inhabitants (111,605 male, 110353 female) (16). The district has 37 rural and 5 urban kebeles (subdistricts). There are one hospital, seven health centers and forty-two health posts.

\section{Study participants}

The study participants for this particular research work were individuals in households and neighbors of laboratory confirmed cases that lived at least for a year in the area and present during data collection. However, children below 6 months, Individuals who had taken anti-malaria drugs within 4 weeks prior to data collection and members of households and neighbors of laboratory confirmed cases with clinical signs and symptoms of malaria (fever, chills and rigor) were excluded.

\section{Study size and sampling technique}

A sample size of 270 was calculated using single population proportion statistical formula by the following assumptions: 95\% level of confidence, $3.5 \%$ margin of error and P (proportion) of 0.095 (17). First, two health centers were purposely selected from Raya Kobo district based on the 2018 monthly high malaria incidence report. Individuals who visited the selected health centers and had laboratory confirmed malaria cases were tracked to their residence for active case investigation. Within two months period, a total of 35 index cases were found microscopic positive for Plasmodium species. Only 20 index cases who fulfilled the inclusion criteria initiated reactive case detection. All members of households and neighbors of laboratory confirmed cases within $200 \mathrm{~m}$ radius were included in the study by using convenience sampling technique (18).

\section{Data collection}

Questionnaire: A structured pre-tested questionnaire was used to collect socio-demographic information, and individual and household level factors related to Plasmodium spp infection via a face to face interview by the principal investigator. 
Blood sample collection, handling and transportation: Finger prick blood specimen was collected for dried blood spot (DBS), RDT and blood film. Three to four drops of blood were immediately spotted on Whatman 3MM filter paper for molecular analysis. The DBS was packaged individually into double zip lock plastic bag with desiccant, and subsequently transported to Woldia General Hospital Laboratory for storage at $-20^{\circ} \mathrm{C}$. Later, it was transferred to Amhara Public Health Institute for PCR analysis.

RDT (CareStartTM Malaria Pf/Pv (HRP2/pLDH) Ag Combo Test): After the pouch open for immediate use, the collected capillary sample was blotted onto the sample pad of the test kit. Approximately, two drops of buffer were added onto the buffer pad and the result was read at the end of 20 minutes.

Blood films: Both thin and thick blood films were prepared for microscopic investigation of Plasmodium spp. The thin blood smear was fixed by carefully dropping methanol using a Pasteur pipette immediately after drying. The methanol-fixed thin smears were allowed to dry completely in air (approximately 2 min) by placing the slides on a flat surface. The prepared blood smears were transported to the nearby health center in a slide box for giemsa staining (19).

\section{Molecular analysis (quantitative-real time PCR)}

DNA Extraction: Briefly, three 3-mm punches of the DBS were punched out and placed into a 1.5-mL Eppendorf tube. The punches inside the Eppendorf tube were treated with ATL buffer, proteinase $K$, and AL buffer with brief vortex and incubation with respective addition. The mixtures were transferred into QIAamp Mini spin column and with subsequent addition of wash buffer AW1 and AW2. The DNA was eluted in $100 \mu \mathrm{L}$ of elution buffer, aliquoted and stored at $-20^{\circ} \mathrm{C}$ until use.

DNA Amplification: Amplification of the Genus and P. falciparum multiplex was performed in a 20-ml reaction tube containing $10.0 \mu \mathrm{L} 2 \mathrm{X} \mathrm{ABI}$ TaqMan buffer, $0.5 \mu \mathrm{l}$ each forward and reverse primer for the Genus, $0.5 \mu \mathrm{l}$ forward and $0.25 \mu \mathrm{l}$ reverse primer $P$. falciparum and $5 \mu \mathrm{l}$ of DNA template. The reactions were performed under the following cycling parameters: initial hot-start at $95^{\circ} \mathrm{C}$ for 15 minutes, followed by 45 cycles of denaturation at $95^{\circ} \mathrm{C}$ for 20 seconds and 45 cycles annealing at $60^{\circ} \mathrm{C}$ for 40 seconds. The correct fluorescence channel was selected for each fluorescently labeled primer set and the cycle threshold values recorded at the end of annealing step. Any sample with a cycle threshold value of 40 or below was considered positive. Both singleplex and multiplex assays were performed for all the samples (20).

\section{Quality control}

The questionnaire was subject to pre-test, and training was given for the data collectors. The RDT kits were checked for expiry dates, and positive and negative blood films were run to check the quality and integrity of Giemsa staining. As for PCR, the positive and negative controls were run accordingly to maintain the quality.

\section{Data analysis}


The data were entered into Epi Data 3.1 version and imported to Statistical Package for Social Sciences (SPSS) version 20 (IBM, USA) for analysis. Bivariable and multivariable logistic regression were performed to assess the association between dependent variable and independent variables. Variables with P-value of $\leq 0.25$ in the bivariable analysis were included in the multivariable logistic regression analysis. Odds ratio was calculated with a confidence interval of $95 \%$; and a P-value $<0.05$ was considered as statistically significant.

\section{Results}

\section{Socio demographic characteristics}

A total of 270 study participants residing in 60 households were enrolled in the study ( 72 from 20 index houses and 198 from 40 neighboring houses). Majority (61\%) of the participants were female. The mean age of the participants was $21.02( \pm 18.6 \mathrm{SD}$ ) years.About $38.9 \%, 32.6 \%$, and $17.0 \%$ of the participants were from Addis Kign Aradom, and Jarota (Table 1).

Table 1

Socio-demographic characteristics of participants in the community of selected health centers in Raya Kobo district, Northeast Ethiopia from February to April 2019 ( $N=270)$

\begin{tabular}{|c|c|c|}
\hline Variable & & Frequency (N/\%) \\
\hline Age (year) & $\begin{array}{l}\leq 15 \\
>15\end{array}$ & $\begin{array}{l}137(50.7) \\
133(49.3)\end{array}$ \\
\hline Sex & $\begin{array}{l}\text { Male } \\
\text { Female }\end{array}$ & 101(37.4) 169(62.6) \\
\hline Residency & $\begin{array}{l}\text { Urban } \\
\text { Rural }\end{array}$ & $\begin{array}{l}81(30.0) \\
189(70.0)\end{array}$ \\
\hline Living in & $\begin{array}{l}\text { Index house } \\
\text { Neighbors house }\end{array}$ & $\begin{array}{l}72(26.7) \\
198(73.3)\end{array}$ \\
\hline Family size & $\begin{array}{l}1-5 \text { members } \\
\geq 6 \text { members }\end{array}$ & $\begin{array}{l}128(47.4) \\
142(52.6)\end{array}$ \\
\hline Kebele & $\begin{array}{l}\text { Aradom } \\
\text { Golesha Addis Kign Jarota }\end{array}$ & $\begin{array}{l}88(32.6) \\
31(11.5) \\
105(38.9) \\
46(17.0)\end{array}$ \\
\hline \multicolumn{3}{|c|}{ Prevalence of asymptomatic Plasmodium spp infection } \\
\hline \multicolumn{3}{|c|}{$\begin{array}{l}\text { The overall prevalence of asymptomatic malaria was } 7.0 \% \text {. RDT, microscopy and PCR detected and } \\
\text { identified 3.0\%, } 5.2 \% \text { and } 12.0 \% \text {, respectively. PCR detected asymptomatic malaria about } 2.7-\text { fold and } \\
2.3 \text {-fold higher than RDT microscopy, respectively. Plasmodium falciparum accounted for } 57.9 \% \text { of } \\
\text { the asymptomatic infections, and the remaining } 42.1 \% \text { was caused by P. vivax (Table } 2 \text { ). }\end{array}$} \\
\hline
\end{tabular}


Table 2

Prevalence of asymptomatic malaria by three malaria diagnostic methods in Raya Kobo district, Northeast Ethiopia from February to April 2019 ( $\mathrm{N}=270)$

\begin{tabular}{|lllll|}
\hline \multirow{2}{*}{ Result } & \multicolumn{2}{l}{ Diagnostic methods } & $\begin{array}{l}\text { Overall } \\
\text { prevalence }\end{array}$ \\
\cline { 2 - 5 } & RDT & Microscopy & PCR & \\
\hline P. falciparum & 4 & 7 & 6 & 11 \\
\hline P. vivax & 4 & 7 & 5 & 8 \\
\hline Total positive (\%) & $8(3.0 \%)$ & $14(5.2 \%)$ & $11(12.0 \%)$ & $19(7.0 \%)$ \\
\hline Total negative (\%) & $262(97 \%)$ & $256(94.8 \%)$ & $81(88.0 \%)$ & $251(93 \%)$ \\
\hline
\end{tabular}

The prevalence of asymptomatic malaria among participants in the index and neighbors' houses was $19.4 \%$ and $2.5 \%$, respectively. The highest prevalence of asymptomatic malaria, $10.5 \%$ was recorded at Addis Kign kebele followed by Aradom Kebele, which was 8.0\% (Table 3).

Table 3

Prevalence of asymptomatic malaria by age, sex, kebeles and relation with index cases in Raya Kobo district, from February to April $2019(\mathrm{~N}=270)$

\begin{tabular}{|lll|}
\hline Variables & & Overall prevalence \% $(\mathrm{N})$ \\
\hline Age & $<15$ & $3.6 \%(5 / 137)$ \\
\cline { 2 - 3 } & $>15$ & $10.5 \%(14 / 133)$ \\
\hline Sex & Male & $7.9 \%(8 / 101)$ \\
\cline { 2 - 3 } & Female & $6.5 \%(11 / 169)$ \\
\hline Kebele & Index house & $19.4 \%(14 / 72)$ \\
\cline { 2 - 3 } & Neighboring house & $2.5 \%(5 / 198)$ \\
& Addis Kign & $10.5 \%(11 / 105)$ \\
\cline { 2 - 3 } & Aradom & $8.0 \%(7 / 88)$ \\
\cline { 2 - 3 } & Golesha & $0 \%(0 / 31)$ \\
\cline { 2 - 3 } & Jarota & $2.2 \%(1 / 46)$ \\
\hline
\end{tabular}

Individuals and household factors associated with Plasmodium spp infection Bivariable and multivariable analyses 
The bivariable analysis of individual and household factors showed significant association with asymptomatic malaria prevalence at P-value $<0.05$ (Table 4). Consequently, individual factors such as age group > 15 years (COR: 3.1 [Cl: 1.09-8.88]) and previous history of malaria (COR: 6.727 [1.91223.668]) showed significant association with Plasmoium spp infection. As in household level factors, participants living in Addis Kign kebele (COR: 2.9 [Cl: 1.11-7.66]), within index houses (COR: 5.5 [Cl: 2.056-14.486]), and family size $\geq 6$ members (COR: 5.3 [Cl: 5.291 (1.504-18.610]) had higher odds of having Plasmodium spp infection (Table 4).

Eight potential factors (age, relation with index cases, kebele, travel history, previous malaria history, family size, wall type and utilization of mosquito's bed net) with P-value $\leq 0.2$ in bivariable analysis were selected and entered into multivariable logistic regression to control confounding effects. After adjusting the confounding effects, only three variables (living with index cases, previous malaria history and family size) showed statistically significant association with Plasmodium species infection (Table 4).

The odds of Pasmodium spp infection in individuals having previous malaria history was 4.0 times higher compared to those who didn't have it. Participants who lived in index houses were 3.9 times at higher odds of getting Plasmodium spp infection than those who lived in neighboring houses. Households who had six or more members had 4.8 times higher in Plasmodium spp infection than families with low members (Table 4). 
Table 4

Bivariable and multivariable analysis of individual and household factors of Plasmodium spp infection in Raya Kobo districts, from February to April $2019(\mathrm{~N}=270)$

\begin{tabular}{|c|c|c|c|c|c|c|}
\hline \multirow[t]{2}{*}{ Variables } & & \multicolumn{2}{|c|}{$\begin{array}{l}\text { Asymptomatic } \\
\text { malaria }\end{array}$} & \multirow{2}{*}{$\begin{array}{l}\begin{array}{l}\text { Bivariable } \\
\text { analysis }\end{array} \\
\text { COR }(95 \% \mathrm{Cl})\end{array}$} & \multirow{2}{*}{$\begin{array}{l}\text { Multivariable } \\
\text { analysis }\end{array}$} & \multirow[t]{2}{*}{$\begin{array}{l}\text { P- } \\
\text { value }\end{array}$} \\
\hline & & Pos & $\mathrm{Neg}$ & & & \\
\hline $\begin{array}{l}\text { Age (in } \\
\text { years) }\end{array}$ & $\begin{array}{l}\leq 15 \\
>15\end{array}$ & $\begin{array}{l}5 \\
14\end{array}$ & $\begin{array}{l}132 \\
119\end{array}$ & $\begin{array}{l}1 \\
3.106(1.086- \\
8.882)\end{array}$ & $\begin{array}{l}1 \\
1.843(0.545- \\
6.236)\end{array}$ & 0.326 \\
\hline Live in & $\begin{array}{l}\text { Index house } \\
\text { Neighboring } \\
\text { house }\end{array}$ & $\begin{array}{l}12 \\
7\end{array}$ & $\begin{array}{l}60 \\
191\end{array}$ & $\begin{array}{l}5.457(2.056- \\
14.486) \\
1\end{array}$ & $\begin{array}{l}3.880(1.275- \\
11.806) \\
1\end{array}$ & $0.017 *$ \\
\hline Family size & $\begin{array}{l}\leq 5 \text { members } \\
\geq 6 \text { members }\end{array}$ & $\begin{array}{l}3 \\
16\end{array}$ & $\begin{array}{l}125 \\
126\end{array}$ & $\begin{array}{l}1 \\
5.291(1.504- \\
18.610)\end{array}$ & $\begin{array}{l}1 \\
4.820(1.260- \\
18.437)\end{array}$ & $0.022 *$ \\
\hline Travel history & $\begin{array}{l}\text { Yes } \\
\text { No }\end{array}$ & $\begin{array}{l}3 \\
16\end{array}$ & $\begin{array}{l}13 \\
238\end{array}$ & $\begin{array}{l}3.433(0.887- \\
13.289) 1\end{array}$ & $\begin{array}{l}1.525(0.305- \\
7.637)\end{array}$ & 0.607 \\
\hline $\begin{array}{l}\text { Malaria } \\
\text { history }\end{array}$ & $\begin{array}{l}\text { Yes } \\
\text { No }\end{array}$ & $\begin{array}{l}16 \\
3\end{array}$ & $\begin{array}{l}111 \\
140\end{array}$ & $\begin{array}{l}6.727(1.912- \\
23.668) \\
1\end{array}$ & $\begin{array}{l}4.030(1.021- \\
15.903)\end{array}$ & $0.047 *$ \\
\hline $\begin{array}{l}\text { Mosquitoes } \\
\text { bed net }\end{array}$ & $\begin{array}{l}\text { Present } \\
\text { Absent }\end{array}$ & $\begin{array}{l}17 \\
2\end{array}$ & $\begin{array}{l}167 \\
84\end{array}$ & $\begin{array}{l}1 \\
0.234(0.053- \\
1.036)\end{array}$ & $\begin{array}{l}1 \\
0.338(0.061- \\
1.875)\end{array}$ & 0.215 \\
\hline Wall type & $\begin{array}{l}\text { Wood with } \\
\text { mud / clay } \\
\text { Others }\end{array}$ & $\begin{array}{l}16 \\
3\end{array}$ & $\begin{array}{l}237 \\
14\end{array}$ & $\begin{array}{l}0.315(0.082- \\
1.210) \\
1\end{array}$ & $\begin{array}{l}0.272(0.048- \\
1.547) \\
1\end{array}$ & 0.142 \\
\hline Kebele & $\begin{array}{l}\text { Addis Kign } \\
\text { Others }\end{array}$ & $\begin{array}{l}12 \\
7\end{array}$ & $\begin{array}{l}93 \\
159\end{array}$ & $\begin{array}{l}2.963(1.127- \\
7.791) \\
1\end{array}$ & $\begin{array}{l}2.571(0.848- \\
7.797) \\
1\end{array}$ & 0.095 \\
\hline
\end{tabular}

\section{Discussion}

Asymptomatic malaria becomes a series challenge in malaria elimination due to low health seeking behaviors of individuals, and is therefore a potential reservoir in sustaining malaria transmission (10).

In this study RDT detected and identified $3 \%$ of the asymptomatic Plasmodium spp infection. This is in line with a study in Debre Elias district, Northwest Ethiopia 4.8\% (21), Southeast Asia 4\% (22), Lao DPR $2.2 \%$ (23), and Haiti $1.78 \%$ (24). On the other hand, the finding of this study was found to be higher than study done in Malo, Southwest Ethiopia with zero case (17) and Northern Senegal with $0.4 \%$ (25). This 
discrepancy might be due to parasitemia level, quality of different RDT products which may differ in detection limits.

In the current study, microscopy detected and identified $5.2 \%$ of asymptomatic infections. This finding is in harmony with study done in Debre Elias district, Northwest Ethiopia 4.2\% (21), Sanja, Northwest Ethiopia 6.8\% (26), Southern central Oromia, Ethiopia 5\% (27) and Southwest Asia 5\% (22). However, this figure is lower than previous studies in Kenya $12.6 \%$ (28) and Tanzania 8\% (29). Lower findings than the current study were reported in Malo, Southwest Ethiopia with no case (17), Myanmar 1.4\% (30), and Haiti with $2.8 \%$ (24). This difference might be due to parasitemia level, variation in transmission setting, and skills of laboratory personnel.

The polymerase chain reaction (PCR) detected and identified $12 \%$ of asymptomatic Plasmodium spp infection. This was higher than previous studies in Ethiopia; with $8.12 \%(17,18)$, Myanmar with $2.3 \%(30)$, Zambia with 8\% (31). However, it was lower than findings in Southeast Asia with 20\% (22), Haiti with $19.1 \%$ (24), Kenya; $20 \%$ \& 33.3\% (28,32), India with 22.6\% (33), and This difference might be due to variation in transmission settings, difference in case investigation, control and preventive measure taken in each country. The portion of infections that is undetectable by microscopy varies between endemic areas and population groups (8). Furthermore, in the present study, only small numbers of samples were run for PCR due to insufficient resource, and this may contribute for the difference.

Moreover, the present study revealed that PCR invariably detected higher proportion of asymptomatic infection with about 2.7 and 2.3 folds higher than RDT and microscopy, respectively. This finding is in agreement with reports from Brazil (34). Therefore, this substantial difference among diagnostics methods can be due to variation in the detection limit of diagnostic methods, in which PCR detects as low as $0.5-5$ parasites $/ \mu$ l of blood while microscopy and RDT detect 50 and 100 parasites $/ \mu$ l of blood respectively (35).

Of overall prevalence of asymptomatic malaria, the predominant Plasmodium spp was P. falciparum with $57.9 \%$ and the remaining $42.1 \%$ was $P$. vivax. This finding is in line with Ethiopian nationwide malaria figure reported by Ministry of Health over which P. falciparum account about $60 \%$ (2). On the contrary, other studies in Ethiopia reported P. vivax was the predominant species in Hadiya zone, Southern Ethiopia (36), and East Shewa zone, Central Ethiopia (37). This difference relies on the heterogeneity of Plasmodium species distribution as a result of environmental and ecological changes.

Reactive case detection has identified Plasmodium spp infection clustered in households and neighbors of index cases, and is highly valuable in low transmission intensity areas (32). The current study identified high prevalence of asymptomatic infection in index houses with $19.4 \%$ (14/72) compared with their neighboring houses with $2.5 \%$ (5/198). This finding is consistent with a study done in Jimma zone, Southwest Ethiopia (18). This difference likely reflects family members of index cases are with equal proximity to the breeding sites of vectors along with likely behaviors and occupations within family. Therefore, the index cases justly denote foci of transmission to family members. This study revealed that 
of the total asymptomatic cases, the prevalence of asymptomatic infection varied with approximately 3 folds higher in index households compared with their neighbors within $200 \mathrm{~m}$ radius.

Comparing the conventional diagnostics tools against PCR (taken as gold standard), the current study revealed that RDT and microscopy had lower sensitivity with $36.4 \%$ and $45.5 \%$, respectively. This result showed that the sensitivity of RDT is by far lower that WHO recommended sensitivity over $95 \%$ at 100 parasites $/ \mu$ l of blood (38). High false negative rate (63.6\%) was identified in RDT. This means that $63.6 \%$ of asymptomatic individuals who actually had malaria remained undetected, and serve as possible reservoirs to continue the transmission dynamics. Low sensitivity and high false negative rates of RDT might be due to parasitic factors (parasitemia level and variation in parasite antigenic structure) and device related factors (RDT shipment and storage conditions, misinterpretation of results). Evidence suggests that the detection capacity RDT get reduced as antigenic variability occurs at density below 500 parasites / $\mu$ l of blood (38).

The current study identified previous malaria history increase 4.0 times the odds of having Plasmodium spp infection. This finding is supported by studies done in Ethiopia $(18,21,26)$. This might be due to relapse or recurrence of infection. Recurrence of infection is due to the persistence of low level of $P$. falciparum in the circulation while relapse is due to the reactivation of hypnozoite which leads to initiation of erythrocytic cycle in case of P. vivax (Sastry and Bhat, 2014). However, these studies also underpinned living with index cases and family size $\geq 6$ members as potential risk factors. Reasonably, the infection is clustered in index cases' houses compared with neighbors' houses and this might be due to equal proximity to vector breeding sites or likely behaviors of family members with the index cases.

\section{Conclusion}

By subsequently followingthe index cases, Reactive case detection had identified foci of malaria transmission withconsiderablyhigher proportionofasymptomatic infectionas compared to the national malaria prevalencesurvey report. The conventional diagnostic methods underestimated the prevalence and only identified below half of PCR confirmed cases. Previous malaria history, living with index cases and family with $\geq 6$ members was associated with the acquisition of Plasmodium spp infection. Therefore, active case investigation should be established in the community and highly sensitive diagnostics method such as PCR should be included in epidemiological survey of asymptomatic carriers in foci investigation and mapping low density infection.

\section{Declarations}

\section{Ethics approval and consent to participate}

The study protocol was evaluated and approved by the Institutional Review Board (IRB) of College of Medicine and Health Sciences, Bahir Dar University; and ethical approval was obtained. Official supporting letters were also obtained from Amhara Public Health Institute and Zonal health offices. 
Moreover, prior to commencing the study, a written informed consent was obtained from each participant aged $\geq 18$ years and assent was obtained from parents /guardians/ in case of participants aged below 18 years. Participant confidentiality and any special data security requirements were maintained and assured. Results of the laboratory examinations that had a direct benefit in the health of the study participants were directly linked to health center; and the participants got their results and treatment duly as required.

\section{Consent for publication}

Individual data such as images and videos did not accompany this particular manuscript and hence consent for publication is not applicable.

\section{Availability of data and materials}

To generate findings of this particular study, data was collected and analyzed based on the stated methods and materials. All the data were incorporated in the manuscript and no supplementary files accompanied the submission. The original data supporting this finding will be available at any time upon request.

\section{Competing interests}

Authors declared they have no conflicting interest.

\section{Funding}

The research project was funded by Bahir Dar University.

\section{Authors' contributions}

YM designed the study, supervised data collection and analyzed data; MA designed the study, and drafted the manuscript; MY designed the study, analyzed data and revised the manuscript, BT participated in data collection and analysis. All authors have read and approved the manuscript

\section{Abbreviations}

RDT: Rapid diagnostic tests; PCR: Polymerase chain reaction; AOR: Adjusted odds ratio; COR: Crude odds ratio; Cl: Confidence interval; WHO: World health organization; FMOH: Federal ministry of health; CSA: Central statistics agency; DNA: Deoxyribonucleic acid 


\section{References}

1. WHO. Fact sheet about Malaria. 2018a [online] Available at: https://www.who.int/news-room/factsheets/detail/malaria [Accessed 31 Dec. 2018].

2. Federal Ministry of Health (FMoH). Ethiopia national malaria guideline 3rd editionFMOH2012. Addis Ababa Ethiopia.

3. WHO. Meeting report of the WHO Evidence Review Group on Low-Density Malaria Infections 2017. [online] Available at: https://www.who.int/malaria/mpac/mpac-oct2017-erg-malaria-low-densityinfections-session2.pdf?ua=1 [Accessed 1 Jan. 2019].

4. Cordray MS, Richards-Kortum RR. Emerging nucleic acid-based tests for point-of-care detection of malaria. The American Journal of Tropical Medicine and Hygiene, 2012;87(2):223-230.

5. WHO. Policy brief on malaria diagnostics in low-transmission settings, 2014[online] Available at: https://www.who.int/malaria/publications/atoz/malaria-diagnosis-low-transmission-settingssep2014.pdf? ua=1 [Accessed 1 Jan. 2019].

6. WHO. World Malaria Report 2018b,Available at: http://apps.who.int/iris/bitstream/handle/10665/275867/9789241565653-eng.pdf(Accessed: 1st January 2019).

7. Deribew A, Dejene T, Kebede B, Tessema GA, Melaku YA, Misganaw A, et al. Incidence, prevalence and mortality rates of malaria in Ethiopia from 1990 to 2015: analysis of the global burden of diseases 2015. Malaria Journal, 2017; 16(1):271.

8. Bousema T, Drakeley C. Determinants of malaria transmission at the population level Cold Spring Harbor Perspectives in Medicine, 2017; a025510.

9. WHO. (2018C) Malaria Surveillance, Monitoring \& Evaluation: A Reference Manual [ONLINE] Available at http://apps.who.int/iris/bitstream/handle/10665/272284/9789241565578-eng.pdf? ua=1. [Accessed 1 January 2019].

10. Harris I, Sharrock WW, Bain LM, Gray KA, Bobogare A, Boaz L, et al. A large proportion of asymptomatic Plasmodium infections with low and sub-microscopic parasite densities in the low transmission setting of Temotu Province, Solomon Islands: challenges for malaria diagnostics in an elimination setting. Malaria Journal, 2010; 9(1):254.

11. Galatas B, Bassat Q, Mayor A. Malaria parasites in the asymptomatic: looking for the hay in the haystack. Trends in Parasitology, 2016; 32(4):296-308.

12. Babiker HA, Abdel-Muhsin AA, Hamad A, Mackinnon MJ, Hill WG, Walliker D. Population dynamics of Plasmodium falciparum in an unstable malaria area of eastern Sudan. Parasitology, 2000; 120(2):105-111.

13. Grueninger, Hamed K. Transitioning from malaria control to elimination: the vital role of ACTs. Trends in Parasitology, 2013; 29(2): 60-64.

14. Schellenberg D. A research agenda for malaria eradication: diagnoses and diagnostics. PLOS Medicine, 2011; 8(1): e1000396. 
15. PMI. Ethiopia Malaria Operational Plan: President's Malaria Initiative,; Addis Ababa, Ethiopia, 2017.

16. CSA. Population and Housing Census Report-Amhara region; CSA- Ethiopia 2007.

17. Tadesse FG, Pett H, Baidjoe A, Lanke K, Grignard L, Sutherland C, et al. Submicroscopic carriage of Plasmodium falciparum and Plasmodium vivax in a low endemic area in Ethiopia where no parasitaemia was detected by microscopy or rapid diagnostic test. Malaria Journal, 2015; 14(1):303.

18. Zemene E, Koepfli C, Tiruneh A, Yeshiwondim AK, Seyoum D, Lee MC, et al. Detection of foci of residual malaria transmission through reactive case detection in Ethiopia.Malaria Journal, 2018;17(1):390.

19. WHO. Malaria Microscopy Quality Assurance Manual - Version 2. WHO. (2016) WHO Malaria elimination: guide for participant. [online] Available at: https://www.who.int/malaria/publications/atoz/9789241549424_eng.pdf [Accessed 1 Jan. 2019$].$

20. PATH. Detection of low level malaria parasite from RDT using PET-PCR method: Standard Operating Protocol. Seattle, USA, 2016.

21. Ayele DG, Zewotir TT, Mwambi HG. Prevalence and risk factors of malaria in Ethiopia.Malaria Journal, 2012;11(1):195.

22. Imwong M, Nguyen TN, Tripura R, Peto TJ, Lee SJ, Lwin KM, et al. The epidemiology of subclinical malaria infections in South-East Asia: findings from cross-sectional surveys in Thailand-Myanmar border areas, Cambodia, and Vietnam.Malaria Journal, 2015;14(1):381.

23. Pongvongsa T, Nonaka D, Iwagami M, Nakatsu M, Phongmany $P$, et al. Household clustering of asymptomatic malaria infections in Xepon district, Savannakhet province, Lao PDR. Malaria Journal, 2016; 15(1):508.

24. Elbadry MA, Al-Khedery B, Tagliamonte MS, Yowell CA, Raccurt CP, Existe A, et al. High prevalence of asymptomatic malaria infections: a cross-sectional study in rural areas in six departments in Haiti. Malaria Journal, 2015; 14(1):510.

25. Littrell M, Sow GD, Ngom A, Ba M, Mboup BM, Dieye Y, et al. Case investigation and reactive case detection for malaria elimination in northern Senegal. Malaria Journal, 2013; 12(1):331.

26. Worku L, Damtie D, Endris M, Getie S, Aemero M. Asymptomatic malaria and associated risk factors among school children in Sanja town, Northwest Ethiopia. International Scholarly Research Notices, 2014.

27. Golassa L, Baliraine FN, Enweji N, Erko B, Swedberg G, Aseffa A. Microscopic and molecular evidence of the presence of asymptomatic Plasmodium falciparum and Plasmodium vivax infections in an area with low, seasonal and unstable malaria transmission in Ethiopia. BMC Infectious Diseases, 2015; 15(1):310.

28. Baliraine FN, Afrane YA, Amenya DA, Bonizzoni M, Menge DM, Zhou G, et al. High prevalence of asymptomatic Plasmodium falciparum infections in a highland area of western Kenya: a cohort study. The Journal of Infectious Diseases, 2009; 200(1):66-74.

29. Sumari D, Mwingira F, Selemani M, Mugasa J, Mugittu K, Gwakisa P. Malaria prevalence in asymptomatic and symptomatic children in Kiwangwa, Bagamoyo district, Tanzania. Malaria 
Journal, 2017; 16(1):222.

30. Zaw MT, Thant M, Hlaing TM, Aung NZ, Thu M, Phumchuea K, et al. Asymptomatic and submicroscopic malaria infection in Kayah State, eastern Myanmar. Malaria Journal, 2017; 16:138:1-7.

31. Stresman GH, Kamanga A, Moono P, Hamapumbu H, Mharakurwa S, Kobayashi T, et al.. A method of active case detection to target reservoirs of asymptomatic malaria and gametocyte carriers in a rural area in Southern Province, Zambia. Malaria Journal, 2010; 9(1):265.

32. Aidoo EK, Afrane YA, Machani MG, Chebore W, Lawson BW, Atieli $\mathrm{H}$, et al. Reactive case detection of Plasmodium falciparum in western Kenya highlands: effective in identifying additional cases, yet limited effect on transmission. Malaria Journal, 2018; 17(1): 111.

33. Chourasia MK, Raghavendra K, Bhatt RM, Swain DK, Valecha N, Kleinschmidt I. Burden of asymptomatic malaria among a tribal population in a forested village of central India: a hidden challenge for malaria control in India. BMCPublic Health, 2017; 147:92-97.

34. Almeida AC, Kuehn A, Castro AJ, Vitor-Silva S, Figueiredo EF, Brasil LW, et al. High proportions of asymptomatic and submicroscopic Plasmodium vivax infections in a peri-urban area of low transmission in the Brazilian Amazon. Parasites \& Vectors, 2018; 11(1):194.

35. Delil RK, Dileba TK, Habtu YA, Gone TF, Leta TJ. Magnitude of malaria and factors among febrile cases in low transmission areas of Hadiya zone, Ethiopia: a facility based cross sectional study. PloS One, 2016;11(5): e0154277.

36. Haji Y, Fogarty AW, Deressa W. Prevalence and associated factors of malaria among febrile children in Ethiopia: a cross-sectional health facility-based study. Acta Tropica, 2016; 155:63-70.

37. WHO. The role of laboratory diagnosis to support malaria disease management. Report of a WHO Technical Consultation, 25-26 October 2004. World Health Organization, Geneva, Switzerland, 2006. 